- Fibers from waste can reinforce and lower the cost of biodegradable plastic materials

- Three wastes were studied as fillers in PHB/Cellulose composites for packaging applications.

- Properties make the composites suitable for some food packaging applications.

- Enhancement of thermoforming ability is observed when using almond shell waste. 
Almond Shell

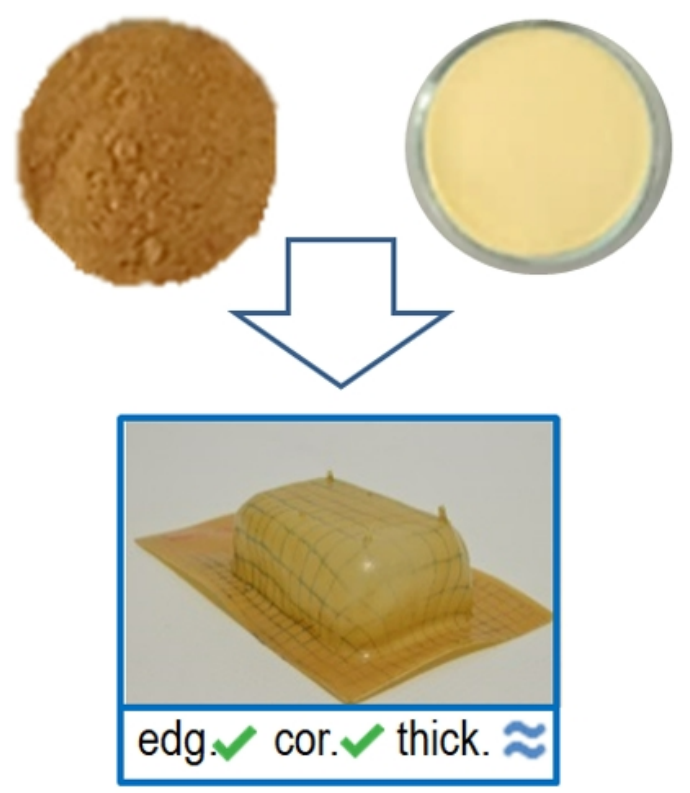

Rice Husk

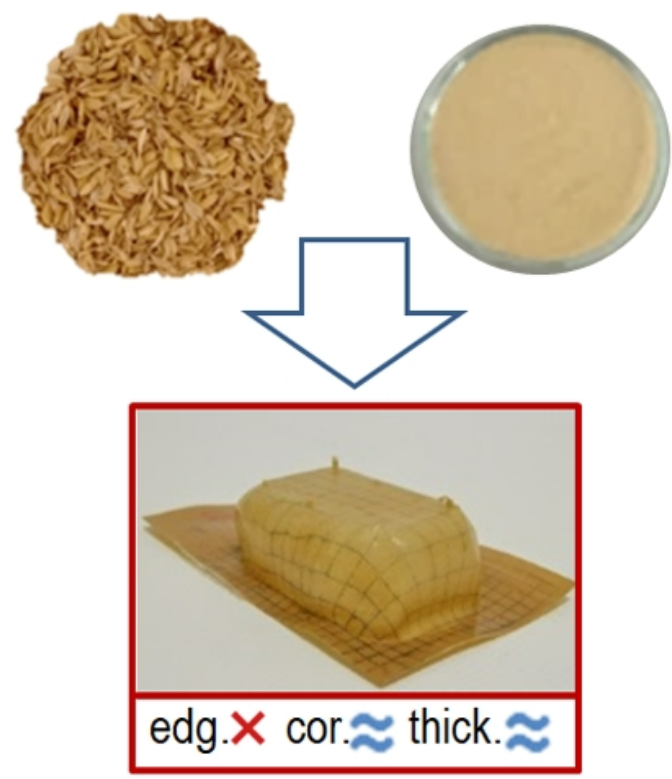

Seagrass

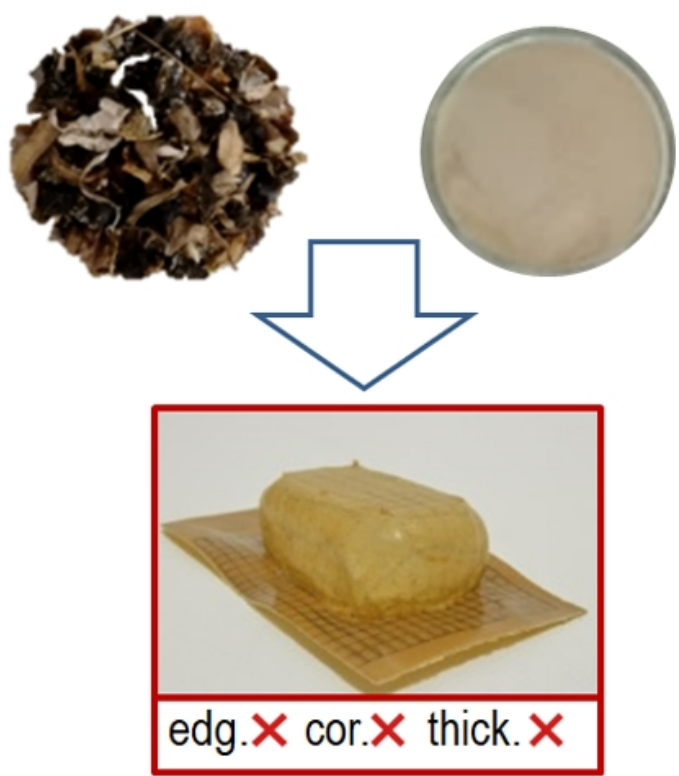




\title{
Biocomposites of different lignocellulosic wastes for sustainable food packaging applications
}

Estefanía Lidón Sánchez-Safont ${ }^{1}$, Abdulaziz Aldureid ${ }^{1}$, José María Lagarón² ${ }^{2}$, José Gámez-Pérez ${ }^{1}$, Luis Cabedo ${ }^{1^{*}}$

1. Polymers and Advanced Materials Group (PIMA), Universitat Jaume I, Spain

2. Novel Materials and Nanotechnology Group, IATA, CSIC, Spain

\begin{abstract}
The suitability of three local lignocellulosic wastes i.e. almond shell (AS), rice husk (RH) and seagrass (SG) as fillers in PHB/Fiber composites applications has been studied. PHB/Fiber composites with 10 phr and 20 phr fiber content were prepared by melt blending. The influence of the fiber type (size, morphology and origin) and content on the morphological, mechanical and thermal properties of the as obtained composites has been assessed. To evaluate the potential use in food packaging applications, the barrier performance to water, thermoforming ability and disintegration in controlled composting conditions of the composites were also studied.

All the fibers have demonstrated to be apt for its use as fillers in PHB/Fiber composites, showing a reinforcing effect without affecting the crystallinity and the disintegration rate of PHB. The thermal stability and the water barrier performance of the composites were reduced by the presence of the fibers. Nevertheless, the addition of AS resulted in the best balance of properties, in terms of permeability and mechanical properties, finding an enhancement of the thermoforming ability of PHB when 10 phr of AS was added.
\end{abstract}

\section{Keywords}


$\mathrm{PHB}$, natural fiber, biodegradable, biocomposite, waste valorization

\section{Introduction}

The combined use of a renewable-based biodegradable polymer together with a natural fiber filler, thus obtaining a biocomposite, pose a sustainable and technically promising alternative to replace the so-called "commodities" plastics in the food packaging sector. There are three main key factors to be considered. In the first place, the reduction of the dependence on petroleum-based materials, while moving towards renewable sources to produce plastics, which would decrease the release of old carbon to atmosphere. Secondly, the use of biodegradable polymer would allow the treatment of the package after its use in the same way as an organic compostable residue, therefore contributing to the reduction of polymeric solid waste that it is destined for landfill or incineration. Finally, the use of natural fibers as fillers opens the way for the valorization of agro-based residues, thus reducing the overall impact of the food production cycle. Altogether, the use of biocomposites made of biodegradable polymers from renewable resources and loaded with fillers derived from agro-based fiber wastes and other by-products, allows a more sustainable packaging by favoring a cradle to cradle concept and promoting the circular economy [1,2].

Among the different commercially available biopolymers, poly(3-hydroxybutirate) (PHB) is one of the most interesting members of the polyhydroxyalkanoates family for food packaging applications. PHB is a thermoplastic that can be easily processed in conventional industrial polymer transformation equipment. It also possesses a good mechanical performance, in terms of stiffness and strength, similar or greater than some of the commodities (such as PP) and good barrier properties (comparable to PET). PHB is biodegradable in composting conditions and other environments such as marine water [3].Despite of the fact that PHB is an excellent candidate for sustainable packaging applications, it still presents some shortcomings that handicaps its extensive 
use in the food packaging sector. PHB presents high intrinsic fragility and due to its high crystallinity, exhibits a narrow processing window, thus hindering its processability in some common food packaging applications, such as thermoforming [3,4]. Another main limitation for its use in the packaging field is its high cost that still exceeds $5 € / \mathrm{kg}$ [3]. In this context, the use of a sustainable, inexpensive and rigid filler may counteract the increase in the price of the material by (a) decreasing the overall cost of the package and/or (b) reducing the thickness necessary in single layer packages $[1,2,5]$

In general, some of the advantages of vegetal fibers are their natural abundance, low density, high specific stiffness and biodegradability [6]. The characteristic properties of vegetal fibers (e.g. morphology, aspect ratio, crystallinity) vary considerably depending on the source, its origin within the plant, the quality of plant locations, the age of the plant and the process used for its extraction They may significantly influence the eventual biocomposite properties [7] Indeed, the high hydrophilicity and thermal instability of vegetal fibers are known to be their main drawbacks for its use as plastic fillers $[1,2,6,8]$

The use of cellulosic waste and agro-based by-products as a source for high performance sustainable fillers represents an attractive and sustainable way of valorization. Numerous studies concerning natural fiber-based biocomposites can be found in the scientific literature. The suitability as fillers of different lignocellulosic fibers, such as wheat straw [9-11], flax fibers [12-14], jute [15], coconut [16], kenaf [17] or olive pomace [11], etc., has been explored. As mentioned before, there is a great variability in the results as a function of the fiber characteristics, but also depending on the matrix type, surface treatment of the fibers and the use of coupling agents, specifically when it comes to mechanical performance. 
In the present work, three local (near Valencia, Spain) cellulosic wastes will be prepared and assessed for its use as fillers in PHB biocomposites: Almond Shell (AS), Rice Husk (RH), and the cleaning beach wastes mainly composed by Seagrass (SG)(Posidonia Oceanica).

Almond is one of the main crops in Valencian Region, and its annual world production is of about 2.7 million of tons (data of 2014)[18]. Shell represents about the $35-75 \%$ of the total fruit weight and is normally discarded or burned as biomass fuel [19]. Few works have been published exploring the use of the almond shell as fillers in composite materials, focusing those cases in matrices like PP [20], PMMA[21] or Urea formaldehyde (UF) resin [19]. However, to the best of our knowledge, its use in biodegradable matrices has not been yet studied in depth.

Regarding the rice husk, the annual world production of rice can reach to more than 740 million tons [18]. Although, Rice Husk has been already employed in different fields, such as bio-fertilizer, silica source, bio-fuel, load in cements or pozzolanic materials [22]; its use as filler in natural fiberbased biocomposites would suppose an eco-friendly way for its valorization. Several studies can be found in bibliography regarding the use of RH as filler in polymeric matrices [23]; although only a few of them concerning PHB [24-27]. Most of those studies, however, are focused on the rice husk derivatives, such as lignin [25], ash [26] or cellulose nanocrystals [27], not on the fibers themselves. Seagrass (Posidonia Oceanica) is the most abundant marine plant in the Mediterranean seabed. The accumulation of tons of dead seagrass in the coast every summer supposes an important impact in touristic beaches and its removal and disposal is an important problem for the coastal city councils. Its high salinity limits its use as common pruning or garden waste. Additionally, the high chlorine content may suppose a problem for its energetic valorization. Therefore, there is a need to find a suitable and sustainable way for the valorization of seagrass residue. Among the few works that have been published to date on the use of seagrass as reinforcement in polymer composites [28- 
30], only one of them focuses on its use as filler in PHA matrices [31], showing a reinforcing effect, a markedly increasing in impact energy-adsorbed capability and an enhancement of biodegradation in marine environment.

Within this context, the present work aims at exploring the valorization of these three different local lignocellulosic wastes (Almond Shell, Rice Husk and Seagrass) in PHB/Fiber composites, especially intended for food packaging applications. In search of an industrial viability, blending of the biocomposites has been conducted by a conventional melt-blending approach. A thorough study on the influence of the fiber characteristics (i.e. morphology and origin) and fiber content on the mechanical and thermal properties of the biocomposites has been carried out. In order to assess the potential applicability in the industrial packaging market, the barrier performance as well as the processability by means of thermoforming is also evaluated, as well as their disintegrability in controlled composting conditions.

\section{Materials and methods}

\subsection{Materials}

A commercial PHB grade (P309-E) was purchased from Biomer ${ }^{\circledast}$ (Krailling, Germany) in pellet form. Micronized almond shell (AS) was kindly supplied by Unió Corporació Alimentària (Reus, Spain). Rice husk $(\mathrm{RH})$ by-product from the rice production process was kindly provided by Herba Ingredients (Valencia, Spain). The residue from the beach cleaning services was supplied by the beach cleaning service of the city council of Benicàssim (Castelló). This residue is mainly composed by seagrass and some algae in smaller proportion (in advance, SG). Other common reagents, like Sodium hydroxide pellets (98\%), acetic acid (99\%) and hydrogen peroxide (30\%) were purchased from Sigma Aldrich.

\subsection{Fiber preparation}


The fiber preparation and purification consisted on a mechanical grinding and sieving to ensure comparable particle size, followed by a two-step purification treatment. The aim of such treatment was double: (a) to obtain a more crystalline cellulose and (b) to improve the surface characteristic of the fibers [32]. For doing so, the major part of waxes, lignin and hemicelluloses present in the raw material had to be removed. Figure 1 shows the appearance of the different fibers used in this work: as received and after the different treatments applied to each fiber.

\section{(Figure 1)}

The almond shell (AS) powder was grinded and sieved through a $140 \mu \mathrm{m}$ mesh. The native rice husk was grinded in an ultracentrifuge mill (Retsch ZM100) at $14000 \mathrm{rpm}$, equipped with a selection sieve of $125 \mu \mathrm{m}$. The SG was visually inspected and plastics, crustaceans and other impurities were manually removed, before further treatments. In order to remove the remaining sand and any water soluble impurities, SG was washed three times with tap water followed by three more washes in distilled water. The clean SG was then allowed to dry at room temperature for one week and then in an oven at $60^{\circ} \mathrm{C}$ for $24 \mathrm{~h}$ before grinding. SG was grinded in identical conditions as the RH. Since it was detected calcium carbonate impurities in SG, prior to the purification treatment with $\mathrm{NaOH}$, a pre-treatment was applied, consisting on a supplementary washing with $3 \% \mathrm{v} / \mathrm{v}$ acetic acid for 1 hour at room temperature. This pre-treatment removed almost all carbonates proceeding from the microscopic crustaceans attached to the SG.

The purification treatment started with a suspension in an alkali solution of $\mathrm{NaOH}(5 \% \mathrm{w} / \mathrm{v})$ and stirred at $80^{\circ} \mathrm{C}$ for two hours. The alkali treatment was followed by a peroxide solution with $\mathrm{H}_{2} \mathrm{O}_{2}$ $\left(10 \% \mathrm{v} / \mathrm{v}\right.$ in distilled water) for 2 hours at $80^{\circ} \mathrm{C}$. Each treatment was applied twice. The fibers were filtered and washed repeatedly in distilled water until neutral $\mathrm{pH}$ is reached. The purified powder was dried at $60^{\circ} \mathrm{C}$ for at least 24 hours before using. All the treatments were conducted maintaining 
a fiber:liquid ratio of 1:20. Finally, all the fibers were grinded again to break the aggregates formed during the filtration process and then sieved in a $140 \mu \mathrm{m}$ mesh. According to the literature, alkaline treatment $(\mathrm{NaOH})$ increases the fiber surface roughness and increments the cellulose exposed whilst peroxide treatment can decrease the hydrophilicity of the fibers thus improving its wettability and, therefore, the fiber-matrix interaction [32].

\subsection{PHB/Fiber composites preparation}

Prior to the blending step, all the treated fibers were dried at $60^{\circ} \mathrm{C}$ for 24 hours. The PHB pellets were dried at $60^{\circ} \mathrm{C}$ for $2 \mathrm{~h}$ using a Piovan DPA 10 (Santa Maria di Sala VE, Italy). Neat PHB and $\mathrm{PHB} /$ Fiber composites of 10 and 20 phr fiber content were prepared by melt blending in an internal mixer (Thermo Haake Rheomix Polylab). The blending step was in all cases of 4.5 minutes at $180^{\circ} \mathrm{C}$ and a rotor speed of $100 \mathrm{rpm}$. In order to reduce thermal degradation during blending, the melt temperature was never allowed to reach $190^{\circ} \mathrm{C}$. The so-obtained blends were then preheated for two minutes at $180^{\circ} \mathrm{C}$ and hot pressed at 3 bar for two minutes, to produce films of $0.35 \mathrm{~mm}$ nominal thickness for mechanical and thermoforming tests and films of $0.20 \mathrm{~mm}$ thickness for biodisintegration and barrier tests. All the samples were stored in a vacuum desiccator at room temperature for 15 days before any characterization, to guarantee full crystallization to take place[33]. The different formulations are named as PHB and PHB/10AS, PHB/10RH and PHB/10SG

for the composites containing $10 \mathrm{phr}$ of the different fibers, and PHB/20AS, $\mathrm{PHB} / 20 \mathrm{RH}$ and $\mathrm{PHB} / 20 \mathrm{SG}$ for the composites containing 20 phr of fibers.

\subsection{Fiber and composites characterization}

The moisture and the ash content of the three different untreated fibers were determined according to the TAPPI standards T210 and T211 respectively, while the treatment yields were calculated referred to the initial fiber dry weight. 
The morphology of the different untreated and treated fibers and the composites was studied by scanning electron microscopy (SEM) using a high-resolution field-emission JEOL 7001F microscope. The average particle size and aspect ratio of the fibers were estimated from the SEM micrographs using image analysis software Fiji ${ }^{\circledR}$ (the number of particles measured for each sample was never below 250). Samples of the composite films were fractured in liquid nitrogen to avoid plastic deformation of the polymer matrix. Both fibers and composites were coated by sputtering with a thin layer of platinum prior to SEM analysis.

The crystallinity of the native and treated fibers was assessed by Wide angle X-ray scattering (WAXS) using a Bruker AXS D4 Endeavor diffractometer. Radial scans of intensity versus scattering angle (20) were recorded at room temperature in the range of 2 to $40^{\circ}(2 \theta)$ (step size $=0.02^{\circ}(2 \theta)$, scanning rate $=4 \mathrm{~s} / \mathrm{step}$ ) with filtered CuKa radiation $(\lambda=1.54 \mathrm{~A})$, an operating voltage of $40 \mathrm{kV}$, and a filament current of $40 \mathrm{~mA}$. The crystallinity was evaluated according to Seagal et al.[34] method, where the crystallinity index $C_{i}$ can be determined with the following equation (1):

$\mathrm{C}_{\mathrm{i}}(\%)=\frac{I_{002}-I_{a m}}{I_{002}} \times 100$

Where $\mathrm{I}_{002}$ is the maximum intensity of the (002) lattice diffraction peak of cellulose located at a diffraction angle of around $22^{\circ}(2 \theta)$ and $\mathrm{I}_{\mathrm{am}}$ is the intensity scattered by the amorphous phase of the sample measured at around $18^{\circ}(2 \theta)$.

Fourier infrared (FT-IR) spectra of the native and treated fibers were recorded by a Jasco FT/IR-6200 equipped with an attenuated total reflection (ATR) accessory in the range of $400-4000 \mathrm{~cm}^{-1}$ in transmission mode.

Thermogravimetric analysis (TGA) of the untreated and treated fibers, as well as the PHB and its composites, was performed with a TG-STDA Mettler Toledo model TGA/STDA851e/LF/1600 analyzer. The samples with an initial mass of typically about $15 \mathrm{mg}$ were heated from 50 to $600^{\circ} \mathrm{C}$ at a heating rate of $10^{\circ} \mathrm{C} / \mathrm{min}$ under nitrogen flow. The thermal stability of the both the fibers and the 
$\mathrm{PHB} /$ Fiber composites was evaluated and the residue at $600^{\circ} \mathrm{C}$ was determined. For the composites, the initial decomposition temperature ( $T_{5 \%}$, temperature at $5 \%$ weight loss) and the maximum decomposition rate temperature (Td) were determined from the weight loss curve and the maximum value of weight loss derivative respectively.

Differential scanning calorimetry (DSC) experiments were conducted on a DSC2 (Mettler Toledo) with an intracooler (Julabo FT900) calibrated with an Indium standard before use. The samples weighing typically $6 \mathrm{mg}$ were first heated from $-20^{\circ} \mathrm{C}$ to $200^{\circ} \mathrm{C}$ at $10^{\circ} \mathrm{C} / \mathrm{min}$ and kept for $5 \mathrm{~min}$ to erase thermal history, followed by cooling to $-20^{\circ} \mathrm{C}$ and heating to $200^{\circ} \mathrm{C}$ at $10^{\circ} \mathrm{C} / \mathrm{min}$. Melting temperature $\left(\mathrm{T}_{\mathrm{m}}\right)$ and enthalpy $\left(\Delta \mathrm{H}_{\mathrm{m}}\right)$ were calculated from the second heating scan. The crystallinity $\left(\mathrm{X}_{\mathrm{c}}\right)$ of the PHB phase of the composites was determined by applying the following expression [35]:

$\mathrm{X}_{\mathrm{c}}(\%)=\frac{\Delta \mathrm{H}_{\mathrm{m}}}{\mathrm{w} \cdot \Delta \mathrm{H}_{\mathrm{m}}^{0}} \times 100$

where $\Delta \mathrm{Hm}(\mathrm{J} / \mathrm{g})$ is the melting enthalpy of the polymer matrix, $\Delta \mathrm{H}^{\circ}{ }_{\mathrm{m}}$ is the melting enthalpy of $100 \%$ crystalline PHB (perfect crystal) (146 J/g) [33] and w is the polymer weight fraction of PHB in the blend.

Dumbbell $350 \mu \mathrm{m}$-thick samples were die-cut from the hot pressed films and tested according to ASTM D638 (Type IV) standard. Tensile tests were conducted in a universal testing machine (Shimatzu AGS-X 500N) at room temperature with a cross-head speed of $10 \mathrm{~mm} / \mathrm{min}$. The samples were conditioned to ambient conditions $\left(25^{\circ} \mathrm{C}\right.$ and $\left.50 \% \mathrm{RH}\right)$ for 24 hours before testing. A minimum of five specimens were measured for each sample and the average results with standard deviation were reported.

The water vapor permeability (WVP) of the PHB/Fiber composites was measured according to the ASTM E96 (2011) gravimetric method, using Payne permeability cups (Elcometer, Hermelle Argenteau, Belgium). Distilled water was placed inside the cup to expose the film (the exposed area 
was $9.6 \times 10^{-4} \mathrm{~m}^{2}$ ) to $100 \%$ relative humidity on one side. Once the films were secured, each cup was placed in a desiccator at $0 \%$ relative humidity provided by silica gel. The cups were weighed periodically $( \pm 0.0001 \mathrm{~g})$ and aluminum foil was used as a control to rule out vapor loss through the seal. WVP was calculated from the steady state permeation slopes obtained from the regression analysis of weight loss data over time. The lower limit of vapor permeability detection of the permeation cells was $\sim 1 \times 10^{-} \mathrm{kg} \mathrm{m} \mathrm{s}^{-1} \mathrm{~m}^{-2}$ Pa-based on the weight loss through the seal in the aluminum samples. All measurements were performed in triplicate.

Vacuum assisted thermoforming study was conducted in a pilot plant (SB 53c, Illig, Helmut Roegele, Germany) equipped with an infrared emitter heating device. The mold used was a female rectangular tray having $40 \times 60 \times 20 \mathrm{~mm}$ (width $\mathrm{x}$ length $\mathrm{x}$ depth) with a maximum draw ratio of 5.2. Rectangular hot pressed sheets of a typical thickness of $350 \mu \mathrm{m}$ were used for this study. The sheets were stamped with a square grid pattern $(0.5 \times 0.5 \mathrm{~cm})$ in order to track the deformation occurred during their mold conformation. For all the experiments, the infrared heater was set to $600^{\circ} \mathrm{C}$, while the heating time was changed in order to control the temperature of the polymer sheet. The sheet surface temperature was measured as a function of heating time, thus obtaining a relation between the heating time and the sheet temperature The thermoformability of PHB and PHB/Fiber composites was evaluated according to the methodology proposed in a previous work [36]. Briefly, this methodology allows classifying the quality of the thermoforming paying attention to three parts of the thermoformed trays: the "edges", "corners" and "thickness distribution". Each one was classified as "bad" (red color, cross sign), "intermediate" (blue color, wave sign) or "good" (green color, tick mark). This classification was used to stablish the thermoforming temperature ranges for each composition. 
Disintegration tests were carried out according to the ISO 20200 standard[37]. Solid synthetic waste was prepared by mixing $10 \%$ of activated mature compost (VIGORHUMUS H-00, purchased from Burás Profesional, S.A., Girona, Spain), 40\% sawdust, 30\% rabbit feed, 10\% corn starch, 5\% sugar, $4 \%$ corn seed oil and $1 \%$ urea. The water content of the mixture was adjusted to $55 \%$. Composite samples were cut from hot pressed films $\left(15 \times 15 \times 0.2 \mathrm{~mm}^{3}\right)$ and buried in compost bioreactors at 4-6 cm depth. The samples were placed inside mesh bags to simplify their extraction and allow the contact of the compost with the specimens. Bioreactors were incubated at $58^{\circ} \mathrm{C}$. The aerobic conditions were guaranteed by mixing the synthetic waste periodically and adding water according to the standard requirements. Three replicates of each sample were removed from the boxes at different composting times for analysis. Samples were washed with water and dried under vacuum at $40^{\circ} \mathrm{C}$ until a constant mass. The disintegration degree was calculated by normalizing the sample weight to the initial weight with equation (3):

$\mathrm{D}=\frac{\mathrm{m}_{\mathrm{i}}-\mathrm{m}_{\mathrm{f}}}{\mathrm{m}_{\mathrm{i}}} \times 100$

where $m_{i}$ is the initial dry mass of the test material and $m_{f}$ is the dry mass of the test material recovered at different incubation stages. The disintegration study was completed taking photographs for visual evaluation.

\section{Results and discussion}

\subsection{Fibers characterization}

Chemical, morphological and thermal characterization of the different fibers before and after the treatment were conducted by means of FTIR, WAXS, TGA and SEM (Figure 2).

Table 1 gathers the moisture and ash content of the fibers as received, the typical composition in terms of Holocellulose, Hemicelluloses, Cellulose and Lignin of the three fibers as reported in the literature, and the treatment yield as the ratio between the initial mass and the mass after the treatment. 


\section{TABLE 1}

The moisture content of the three residues is below $10 \%$ in all cases after grinding and drying. The ash content in natural fibers can be attributed to the presence of minerals [38], i.e. the presence of silica in the rice husk [23] and calcium carbonate in the seagrass, as will be further discussed. The composition in terms of their major structural components, holocellulose (hemicellulose and cellulose) and lignin is also gathered in Table 1. Holocellulose content is, for the three fibers, the major component (ranging from 50 to $60 \%$ ). AS is the one with highest expected cellulose content. The amount of lignin is similar for the three residues studied. The two-step treatment applied to the fiber powder aims formerly at removing all the non-cellulosic fraction of the material. Hence, the yield of the process is higher for those fiber sources with highest cellulose content.

In Fig. 2 are plotted the FTIR spectra of the three fibers before and after the purification treatment. The band present in the absorbance region of $1700-1750 \mathrm{~cm}^{-1}$ is ascribed in the literature to either acetyl and carbonyl groups from carboxylic ester linkages in hemicelluloses and lignin [20,39], or to pectin, wax and natural fats $[40,41]$. In any case, this band should not be present in pure cellulose. In all three treated fibers this band disappears, evidencing the removal of the major part of noncellulosic components by the chemical treatment. Also, the band in the $1200-1250 \mathrm{~cm}^{-1}$ region, ascribed to -C-O stretching vibration of the acetyl groups in lignin and hemicelluloses, is reduced. The reduction of this band after treatment in AS and RH spectrum confirms the partial removal of these components $[20,40]$. The peak at $798 \mathrm{~cm}^{-1}$ in untreated $\mathrm{RH}$ is ascribed to silica vibration bonds and disappears after the purification treatment .The removal of the silica could happen by reaction with $\mathrm{NaOH}$ in accordance to Ndazi et al. [42]. With respect to the SG, the untreated SG spectrum presents a well-defined peak at $877 \mathrm{~cm}^{-1}$ and an intense band at $1420 \mathrm{~cm}^{-1}$. These signals could be related with the calcium carbonate impurities also detected in the WAXS pattern (shown in Fig 2. 
b). After the treatment, the band at $877 \mathrm{~cm}^{-1}$ disappears and the band in the region $1290-1570 \mathrm{~cm}^{-1}$ is clearly reduced. These variations are indicative of the elimination of the major part of the calcium carbonate, as intended in the pre-treatment with acetic acid. Finally, the broad band around 3300 $\mathrm{cm}^{-1}$ corresponds to $-\mathrm{OH}$ vibrations in cellulose and is clearly higher in treated fibers. According to Ndazi et al. [39] the increased intensity of this band could be related to a higher presence of the more reactive $-\mathrm{OH}$ groups in the fiber surfaces, which was the second objective of the fiber treatment.

\section{FIGURE 2}

Wide-angle X-ray scattering experiments were conducted in both untreated and treated fibers in order to estimate the crystallinity index $\left(C_{i}\right)$ of the fibers. Figure $2 b$ shows the WAXS patters of untreated and treated AS, RH and SG. Three different main peaks located at $2 \theta$ of around $16^{\circ}, 22^{\circ}$ and $34^{\circ}$ are observed in all samples. These peaks are characteristics of (110), (002) and (004) planes of cellulose type I $[43,44]$. The presence of these main peaks after treatment indicates that cellulose type I crystalline structure does not change with the chemical attack. The peaks observed in the untreated SG diffraction patterns correspond to silica, calcium carbonate and calcium oxalate; which, according to several authors, are commonly found impurities in sea biomass $[44,45]$.

The crystallinity index calculated with Eq. 2 after Seagal method [34] for the different fibers before and after treatment is listed in Fig. 2c. The values obtained are in agreement with the ones reported in the literature for similar raw materials and cellulose extracted from them by other procedures [45-47]. The increased crystallinity observed in all cases after treatment could be related with the removal of lignin and hemicelluloses (which are amorphous in nature), present in untreated lignocellulosic fibers [41]. In case of the SG the intensity of the peaks corresponding to silica, calcium carbonate and oxalate was also reduced, similarly to the results found by Bettaieb et al. [45]. The highest crystallinity determined in both untreated and treaded fibers corresponds to $\mathrm{RH}$. 
In Figure $2 \mathrm{~d}$ the DTG curves of the untreated and treated AS, RH and SG are shown. The thermal degradation of untreated fibers occurs in a wide range of temperatures comprised between 200 and $600^{\circ} \mathrm{C}$, corresponding to the thermal decomposition of their main components (pectin, hemicelluloses, lignin and cellulose) [48]. Hemicelluloses started their decomposition at around $200^{\circ} \mathrm{C}$ up to 310 . Cellulose decomposition takes place at higher temperatures in the rage $315-400^{\circ} \mathrm{C}$ with a maximum weight loss rate at around $350^{\circ} \mathrm{C}$. Lignin decomposition takes place slowly during the whole range of fiber degradation [49].

As it can be observed in figure $2 \mathrm{~d}$, after treatment, the shoulder located between 200 and $310^{\circ} \mathrm{C}$ has been clearly reduced in all cases and a much narrower main degradation peak was found. These findings can be attributed to the partially removal of non-cellulosic components such as hemicelluloses and lignin [28] and they are consistent with the FTIR and WAXS results. Also, the main degradation peak was slightly shifted towards lower temperature. Ndacy et al [42] suggest that the displacement could be related with the removal of cementing material during the alkali treatment. The small shoulder located around $450{ }^{\circ} \mathrm{C}$ in treated fibers indicates that there is still some lignin remaining after treatment. It may suggest that the alkaline and peroxide treatment for these residues has been more efficient in the removal of hemicelluloses, fats and waxes than in the case of lignin.

Figure 3 shows the SEM micrographs of almond shell, Rice husk and Seagrass fibers before and after alkaline and peroxide treatment. The average size and the aspect ratio were estimated by image analysis.

\section{FIGURE 3}

Almond Shell powder (Figure 3a) is mainly composed by particles of irregular shape. The average size of the particles is about $45 \mu \mathrm{m}$, and its aspect ratio is estimated to be around 2 . The biggest 
particles observed in Fig. 3a and Fig. 3b, can be described as aggregates of smaller particles. A kind of fibrillary structure is revealed in the biggest particles of the treated AS (see arrow in Fig. 3b). The particle surface in the treated AS is characterized by a high roughness and porosity (see Fig. 3c), however the average size, aspect ratio and irregular shape was not modified by the treatment.

Native $\mathrm{RH}$ powder is composed by particles of a broad range of sizes and different morphologies (Fig. 3d). Big particles (rod and rectangular junks) as well as small fibers can be observed. After the treatment, the presence of big junks is more scarce and fibrillary shaped particles with more homogeneous size distribution can be observed. The average particle size is estimated of ca.70 $\mu \mathrm{m}$ and the aspect ratio of particles is of about 7. Figure $3 f$ shows a higher magnification detail of a RH particle, where it can be appreciated the fibrous morphology.

Seagrass raw powder (Fig. 3g) is composed by a mixture of bigger and irregular shaped particles and smaller fibrillary particles. The heterogeneous aspect of this powder is due to its nature, since this waste is formed mainly by Posidonia Ocenica (balls and leaves) but also by accessory algae and some small sea sponges and corals. In Fig 3g, it can be seen that some of the big particles present a tubular (hollow) structure. After treatment, Figure 3h, some irregular shaped particles can be observed but a larger proportion of small-sized fibrillary particles. Upon magnification, a clear fibrillary structure with smooth surface is manifested (Fig. 3i). The average particle size of the smallest particles is estimated of $25 \mu \mathrm{m}$ and up to $200 \mu \mathrm{m}$ for the longer fibers and the aspect ratio ranges from 2 up to 15.

\subsection{Composites characterization}

After the incorporation of the fibers to the PHB as described in experimental section, the composites were analyzed as follows.

\subsubsection{Scanning electron microscopy (SEM)}


The morphology of PHB/fiber composites was studied by SEM on cryofractured surfaces. Representative micrographs of the composites studied are displayed in Figure 4. Low magnification images of each composition have been used to present the fiber distribution within the PHB matrix. High magnification images have been used to show the interfacial interaction between the fiber and the polymer.

\section{FIGURE 4}

For all the composites, homogeneous distribution of the fibers was observed in all cases, i.e. individual fibers are detected homogeneously distributed along the polymer matrix, whilst the presence of fiber aggregates was not detected. These findings confirm that an effective compounding was achieved.

With respect to the fiber-matrix interaction, in all three cases, no clear pull-out effect has been found; on the contrary, broken individual fibers are detected throughout the cryofractured surface, thus revealing some interaction and a certain degree of load transfer between the matrix and the fiber. This interaction could be explained by the presence of reactive - $\mathrm{OH}$ groups created during the fiber treatment, thus improving the wettability of the fibers. [32].

However, the observation of the high magnification micrographs may unveil some differences among the fibers with respect to the interphase. The AS fiber presented in Fig.4c may exhibit higher degree of interaction than either RH or SG (in Fig.4f and Fig.4i, respectively). This statement is derived from the fully covering of the fiber by the PHB for the AS, whereas both the RH and the SG exhibit a small gap at the interface (showing some detachment of the fiber). The differences could be attributed to higher and favorable roughness of the AS fiber surface, with respect to the other ones (see Fig.3c). The presence of small pinholes on the AS fiber surface (c.f. Fig.4c) may enable the penetration of the molten polymer during compounding, which converts after cooling in an effective mechanical anchorage, yielding to a more effective adhesion. 


\subsubsection{Thermogravimetric analysis (TGA)}

Thermal stability of PHB and PHB/fiber composites has been studied by TGA. The onset degradation temperature ( $T_{5 \%}$, calculated as the temperature at which a $5 \%$ weight loss occurs), the maximum degradation rate temperature corresponding to the main degradation steps $\left(\mathrm{T}_{\mathrm{d} 1}, \mathrm{~T}_{\mathrm{d} 2}\right.$, corresponding to the DTG peaks for (1) the PHB matrix and (2) the cellulose) and the residue (\%) at $600{ }^{\circ} \mathrm{C}$ were determined; results are summarized in Table 2.

\section{TABLE 2}

The thermal degradation of neat PHB takes place abruptly in a single weight loss step at $295^{\circ} \mathrm{C}$. As it has been reported, PHB degrades by the random chain scission mechanism leading to a reduction of molecular weight and resulting in the formation of volatile products such as crotonic acid [50]. Earlier thermal degradation was observed in all cases with the incorporation of the natural fibers. However, the thermal stability of PHB seems to be affected by both the filler content and the fiber type. The addition of $10 \mathrm{wt} . \% \mathrm{RH}$ and AS fibers does not significantly alter the thermal stability of $\mathrm{PHB}$, but the incorporation of $10 \mathrm{wt} . \%$ SG lead to a decrease in the onset and peak temperature of 14 and $21^{\circ} \mathrm{C}$, respectively. For the samples containing $20 \mathrm{wt} \%$ of fiber, the SG fibers reduces the maximum degradation temperature in $25^{\circ} \mathrm{C}$ while the incorporation of $\mathrm{RH}$ and $\mathrm{AS}$ reduces this temperature in 12 and $14^{\circ} \mathrm{C}$ respectively. Other authors reported the reduction of thermal stability of biopolyesters by the introduction of cellulosic fibers [31,46,51].

\subsubsection{Differential scanning calorimetry (DSC)}

The influence of the amount and filler type in crystallization and melting behavior of PHB has been studied by DSC measurements. The main thermal parameters, obtained from second heating scans after thermal history erasing, are summarized in table 2. 
Neat PHB present the melting temperature at $171.3^{\circ} \mathrm{C}$. The PHB crystallinity degree calculated by means of eq. (1) is $74.7 \%$. Neither the melting temperatures nor the crystallinity degree seem to be significantly affected by the presence of the different type and amount of fibers. These results are in agreement with other works reported in bibliography about polyhydroxyalkanoates filled with other cellulosic fibers $[11,52,53]$.

\subsubsection{Mechanical properties}

The mechanical behavior of PHB and its composites with 10 and 20 phr of Almond Shell, Rice Husk and Seagrass has been studied by tensile tests up to failure. Young Modulus, Tensile strength and elongation at break of the different composites are summarized in Fig. 5.

\section{FIGURE 5}

The mechanical properties of natural fiber reinforced composites depend on a number of parameters such as volume fraction of the fibers, fiber aspect ratio, fiber-matrix adhesion, stress transfer at the interface, and orientation. The tensile strength is more sensitive to the matrix properties and fiber-matrix adhesion whereas the modulus is more dependent on the fiber properties (whenever good interaction is achieved) [8].

A slight increase in the Tensile Modulus of Elasticity is observed for all the samples when the fibers are incorporated. A positive dependence on the increase in the modulus with the fiber content is found for the AS and RH, while no differences between them are detected; however, for the SG, this trend is not visible. Moreover, this latter fiber yield to higher values of modulus of elasticity than AS and $\mathrm{RH}$. This difference, nevertheless, is not relevant (below 10\%)

With respect to the tensile strength and elongation at break, a clear decrease in both parameters was found with the fibers incorporation. The decrease in both parameters can be attributed to the intrinsic brittleness of the PHB matrix in addition to the stress concentrator effect of the fibers. Thus, 
the biggest particles would be acting as flaws in a brittle polymeric matrix, causing premature failure and not showing any reinforcement effect. Accordingly, this drop in tensile strength and elongation at break is more severe in composites containing the highest content of fibers ( $20 \mathrm{phr}$ ) and especially for PHB/SG composites (where particles were the largest, according to SEM observations). These drawbacks could be in theory improved by enhancing the interaction between the fiber and the matrix and will be the scope of future works.

\subsubsection{Barrier performance}

In terms of barrier performance of the biocomposites, an increase in Water Vapor Permeability was observed for all composites with respect to the neat PHB (as shown in Fig. 6). This increment was more pronounced with an increase in the filler content for all the studied cases. Despite of the fact that the drop in barrier performance is significant in all cases, the incorporation of AS had the less impact in WVP when compared with the two other fillers. Similar results were reported in bibliography for natural filler reinforced composites [54], in which the increase in WVP was ascribed to the higher hygroscopicity of the fibers and preferential paths at the fiber matrix interface, with respect to the neat polymer matrix.

\section{FIGURE 6}

\subsubsection{Thermoforming}

Thermoforming is a most popular processing technology in the food packaging sector and PHB is known to be difficult to thermoform due to a low melt elasticity of the sheet while having a narrow processing window [36]. The addition of a rigid fiber to a highly crystalline polymer would (a priori) most probably lead to a decrease in the thermoforming capacity of the polymer. However, as shown in Fig. 7b, the incorporation of $10 \mathrm{phr}$ of AS to the PHB does not affect negatively to the 
thermoformability; rather on the contrary, a slight improvement in the quality of the thermoformed tray has been found.

\section{FIGURE 7}

In Fig. 7 is summarized the evolution of thermoformability of PHB and PHB/10AS biocomposites as a function of temperature. As it can be observed in figure 7a the thermoformability of PHB is slightly improved with the addition of 10 phr Almond Shell: thickness distribution and mold reproduction ("edges" and "corners") are enhanced with respect to the pristine PHB. The thermoforming temperature range, with acceptable results obtained (shown in Fig. 7 d) is surprisingly also extended. This unexpected enhancement of thermoformability performance achieved for the $\mathrm{PHB} / 10 \mathrm{AS}$ composites may improve the use of this natural fiber-based biocomposites, especially in the food packaging industry. Nevertheless, further investigation is currently being performed, to shed light on this behavior.

\subsubsection{Disintegration in composting conditions}

$\mathrm{PHB}$ and PHB/Fiber composites disintegration in composting conditions was evaluated according to the ISO 20200 standard. The disintegration rate was determined by the measuring weight loss of the samples as a function of composting time. Results are represented in figure 8 .

No appreciable weight loss was detected until the $20^{\text {th }}$ day of composting. From that day the disintegration rate increases abruptly. Total disintegration (considered when no fragments bigger than $2 \mathrm{~mm}$ can be recovered from compost) was reached at 35 days of composting. These findings are in agreement with previous reports [55].

\section{FIGURE 8}


No remarkable differences in weight loss rate were found among the different compositions studied, concluding that neither the fiber type nor the fiber content alters significantly the disintegration rate of PHB in the compositions range studied.

Figure 9 show pictures of the samples at 0 and 28 days of composting. The visual examination of the samples reveals an evident surface roughening at the $4^{\text {th }}$ week of the compost assay, as well as clear physical changes. These observations are in accordance with a disintegration phenomenon that occurs by a gradually microorganism erosion from the surface to the bulk, as it has been reported in literature[55-57].

\section{FIGURE 9}

\section{Conclusions}

Three different lignocellulosic wastes (almond shell, rice husk and seagrass) were compared as fillers in PHB/fiber composites obtained by melt blending with fiber contents up to 20 phr. The influence of the fiber type and the fiber content on morphology, thermal, mechanical, barrier properties, compostability and processability of PHB/fiber composites was studied.

Even though the type and content of the fibers did not affect the crystallization behavior of PHB, their differences in size and morphology induce some variations in the composite properties. SG residues are formed by a mixture of particles with a wide range of sizes and shapes, with high presence of impurities. RH fibers are characterized by a fibrillary shape with a smooth surface and high aspect ratio. AS, on the other hand, present irregular spheroidal shape with a very porous surface.

All the studied fibers were suitable for their application in the development of fully compostable biocomposites for packaging applications. In that sense, all the fibers have demonstrated a mechanical reinforcing effect in terms of increase of elastic modulus, although the resulting barrier properties and thermal stability decreased in the presence of the fibers with respect to neat PHB. 
In spite of the low aspect ratio of AS in comparison with SG and RH, the particular characteristics of this residue seem to favor the mechanical anchoring of the polymer into its surface. It is worth to point out that the incorporation of AS supposed the smallest increase in permeability and the enhanced of the thermoformability of PHB (with the addition of 10 phr AS).

These promising results suppose an interesting starting point for the valorization of these wastes in industrial food packaging applications.

\section{Acknowledgements}

The authors would like to thank the financial support for this research from Ministerio de Economia y Competitividad (AGL2015-63855-C2-2-R), Pla de Promoció de la Investigació de la Universitat Jaume I (UJI-B2016-35) and H2020 EU Project YPACK (H2020-SFS-2017-1, Reference 773872). Authors would like to acknowledge Servicios Centrales de Instrumentación (SCIC) of Universitat Jaume I for the use of FTIR, WAXS, TGA, DSC and SEM. We are also grateful to Raquel Oliver and Jose Ortega for experimental support.

\section{References}

[1] Berthet M-A, Angellier-Coussy H, Guillard V, Gontard N. Vegetal fiber-based biocomposites: Which stakes for food packaging applications? J Appl Polym Sci 2016;133. doi:10.1002/app.42528.

[2] Väisänen T, Haapala A, Lappalainen R, Tomppo L. Utilization of agricultural and forest industry waste and residues in natural fiber-polymer composites: A review. Waste Manag 2016;54:62-73. doi:10.1016/j.wasman.2016.04.037. 
[3] Bugnicourt E, Cinelli P, Lazzeri A, Alvarez V. Polyhydroxyalkanoate (PHA): Review of synthesis, characteristics, processing and potential applications in packaging. Express Polym Lett 2014;8:791-808. doi:10.3144/expresspolymlett.2014.82.

[4] Philip S, Keshavarz T, Roy I. Polyhydroxyalkanoates: biodegradable polymers with a range of applications. J Chem Technol ... 2007;247:233-47. doi:10.1002/jctb.

[5] Mohanty a. K, Misra M, Hinrichsen G. Biofibres, biodegradable polymers and biocomposites: An overview. Macromol Mater Eng 2000;276-277:1-24. doi:10.1002/(SICI)1439-2054(20000301)276:1<1::AID-MAME1>3.0.CO;2-W.

[6] George M, Chae M, Bressler DC. Composite materials with bast fibres: Structural, technical, and environmental properties. Prog Mater Sci 2016;83:1-23. doi:10.1016/j.pmatsci.2016.04.002.

[7] Pandey JK, Ahn SH, Lee CS, Mohanty AK, Misra M. Recent Advances in the Application of Natural Fiber Based Composites. Macromol Mater Eng 2010;295:975-89. doi:10.1002/mame.201000095.

[8] Saheb DN, Jog JP. Natural fiber polymer composites: A review. Adv Polym Technol 1999;18:351-63. doi:10.1002/(SICI)1098-2329(199924)18:4<351::AID-ADV6>3.3.CO;2-O.

[9] Avella M, Martuscelli E, Pascucci B, Raimo M, Focher B, Marzetti A. A new class of biodegradable materials: Poly-3-hydroxy-butyrate/steam exploded straw fiber composites. I. Thermal and impact behavior. J Appl Polym Sci 1993;49. doi:10.1002/app.1993.070491205.

[10] Avella M, G. LA ROTA, E. MARTUSCELLI, RAIMO M. Poly(3-hydroxybutyrate-co-3hydroxyvalerate) and wheat straw fibre composites: thermal, mechanical properties and 
biodegradation behaviour. J Mater Sci 2000;5:829-36.

[11] Berthet M, Angellier-coussy H, Machado D, Hilliou L, Staebler A, Vicente A, et al. Exploring the potentialities of using lignocellulosic fibres derived from three food by-products as constituents of biocomposites for food packaging. Ind Crop Prod 2015;69:110-22. doi:10.1016/j.indcrop.2015.01.028.

[12] Wong S, Shanks R, Hodzic A. Properties of poly(3-hydroxybutyric acid) composites with flax fibres modified by plasticiser absorption. Macromol Mater Eng 2002;287. doi:10.1002/1439-2054(200211)287:10\&lt;647::AID-MAME647\&gt;3.0.CO;2-4.

[13] Lee SG, Choi S-S, Park WH, Cho D. Characterization of surface modified flax fibers and their biocomposites with PHB. Macromol Symp 2003;197.

[14] Shanks RA, Hodzic A, Wong S. Thermoplastic biopolyester natural fiber composites. J Appl Polym Sci 2004;91. doi:10.1002/app.13289.

[15] Ma H, Joo CW. Investigation of jute-lignin-poly (3-hydroxybutyrate) hybrid biodegradable composites with low water absorption. Fibers Polym 2011;12:310-5. doi:10.1007/s12221011-0310-2.

[16] Macedo JDS, Costa MF, Tavares MIB, Thiré RMSM. Preparation and characterization of composites based on polyhydroxybutyrate and waste powder from coconut fibers processing. Polym Eng Sci 2010;50. doi:10.1002/pen.21669.

[17] Kuciel, S., Liber-Kneć A. Biocomposites based on PHB filled with wood or kenaf fibers. Polimery/Polymers 2011;56:218-23.

[18] Food and Agriculture organization of the United Nations. (FAOSTAT Data- base) n.d. 
[19] Pirayesh H, Khazaeian A. Using almond (Prunus amygdalus L.) shell as a bio-waste resource in wood based composite. Compos Part B Eng 2012;43:1475-9. doi:10.1016/j.compositesb.2011.06.008.

[20] El Mechtali FZ, Essabir H, Nekhlaoui S, Bensalah MO, Jawaid M, Bouhfid R, et al. Mechanical and Thermal Properties of Polypropylene Reinforced with Almond Shells Particles: Impact of Chemical Treatments. J Bionic Eng 2015;12:483-94. doi:10.1016/S1672-6529(14)601396.

[21] Sabbatini A, Lanari S, Santulli C, Pettinari C. Use of Almond Shells and Rice Husk as Fillers of Poly(Methyl Methacrylate) (PMMA) Composites. Materials (Basel) 2017;10:872. doi:10.3390/ma10080872.

[22] Hamzeh Y, Ziabari KP, Torkaman J, Ashori A, Jafari M. Study on the effects of white rice husk ash and fibrous materials additions on some properties of fiber-cement composites. J Environ Manage 2013;117:263-7. doi:10.1016/j.jenvman.2013.01.002.

[23] Arjmandi R, Hassan A, Majeed K, Zakaria Z. Rice Husk Filled Polymer Composites 2015;2015.

[24] Wu C. Preparation and Characterization of Polyhydroxyalkanoate Bioplastic-Based Green Renewable Composites from Rice Husk 2014:384-92. doi:10.1007/s10924-014-0662-y.

[25] Bertini F, Canetti M, Cacciamani A, Elegir G, Orlandi M, Zoia L. Effect of ligno-derivatives on thermal properties and degradation behavior of poly (3-hydroxybutyrate ) -based biocomposites. Polym Degrad Stab 2012;97:1979-87. doi:10.1016/j.polymdegradstab.2012.03.009.

[26] Alberti LD, Souza OF, Bucci DZ, Barcellos IO. Study on Physical and Mechanical Properties of PHB Biocomposites with Rice Hull Ash. Mater Sci Forum 2014;775-776:557-61. 
doi:10.4028/www.scientific.net/MSF.775-776.557.

[27] Seoane IT, Fortunati E, Puglia D, Cyras VP, Manfredi LB. Development and characterization of bionanocomposites based on poly(3-hydroxybutyrate) and cellulose nanocrystals for packaging applications. Polym Int 2016;65:1046-53. doi:10.1002/pi.5150.

[28] Fortunati E, Luzi F, Puglia D, Petrucci R, Kenny JM, Torre L. Processing of PLA nanocomposites with cellulose nanocrystals extracted from Posidonia oceanica waste: Innovative reuse of coastal plant. Ind Crops Prod 2015;67:439-47. doi:10.1016/j.indcrop.2015.01.075.

[29] Ferrero B, Fombuena V, Fenollar O, Boronat T, Balart R. Development of natural fiberreinforced plastics (NFRP) based on biobased polyethylene and waste fibers from Posidonia oceanica seaweed. Polym Compos 2015;36:1378-85. doi:10.1002/pc.23042.

[30] Khiari R, Marrakchi Z, Belgacem MN, Mauret E, Mhenni F. New lignocellulosic fibresreinforced composite materials: A stepforward in the valorisation of the Posidonia oceanica balls. Compos Sci Technol 2011;71:1867-72. doi:10.1016/j.compscitech.2011.08.022.

[31] Seggiani M, Cinelli P, Mallegni N, Balestri E, Puccini M, Vitolo S, et al. New Bio-Composites Based on Polyhydroxyalkanoates and Posidonia oceanica Fibres for Applications in a Marine Environment. Materials (Basel) 2017;10. doi:10.3390/ma10040326.

[32] Melo JDD, Carvalho LFM, Medeiros AM, Souto CRO, Paskocimas CA. A biodegradable composite material based on polyhydroxybutyrate (PHB) and carnauba fibers. Compos Part B Eng 2012;43:2827-35. doi:10.1016/j.compositesb.2012.04.046.

[33] Corre Y-M, Bruzaud S, Audic J-L, Grohens Y. Morphology and functional properties of commercial polyhydroxyalkanoates: A comprehensive and comparative study. Polym Test 
2012;31:226-35. doi:10.1016/j.polymertesting.2011.11.002.

[34] Segal L, Creely JJ, Martin AE, Conrad CM. An Empirical Method for Estimating the Degree of Crystallinity of Native Cellulose Using the X-Ray Diffractometer. Text Res J 1959;29:786-94. doi:10.1177/004051755902901003.

[35] Carli LN, Crespo JS, Mauler RS. PHBV nanocomposites based on organomodified montmorillonite and halloysite: The effect of clay type on the morphology and thermal and mechanical properties. Compos Part A Appl Sci Manuf 2011;42:1601-8.

doi:10.1016/j.compositesa.2011.07.007.

[36] González-Ausejo J, Sanchez-Safont E, Lagaron JM, Olsson RT, Gamez-Perez J, Cabedo L. Assessing the thermoformability of poly(3-hydroxybutyrate-co-3hydroxyvalerate)/poly(acid lactic) blends compatibilized with diisocyanates. Polym Test 2017;62:235-45. doi:10.1016/j.polymertesting.2017.06.026.

[37] UNE-EN ISO. UNE-EN ISO 20200 Determinación del grado de desintegración de materiales plásticos bajo condiciones de compostaje simuladas en un laboratorio 2006.

[38] T 211 om-02. Ash in wood, pulp, paper and paperboard: combustion at $525^{\circ} \mathrm{C}$. TAPPI Test Methods 2002.

[39] Ndazi BS, Karlsson S, Tesha J V., Nyahumwa CW. Chemical and physical modifications of rice husks for use as composite panels. Compos Part A Appl Sci Manuf 2007;38:925-35. doi:10.1016/j.compositesa.2006.07.004.

[40] Chanda AK, Hazra A, Praveen Kumar M, Neogi S, Neogi S. Chemical treatments of rice husk filler and jute fiber for the use in green composites. Fibers Polym 2015;16:902-10. doi:10.1007/s12221-015-0902-3. 
[41] Johar N, Ahmad I, Dufresne A. Extraction , preparation and characterization of cellulose fibres and nanocrystals from rice husk. Ind Crop Prod 2012;37:93-9. doi:10.1016/j.indcrop.2011.12.016.

[42] Ndazi BS, Nyahumwa C, Tesha J. Chemical and thermal stability of rice husks against alkali treatment. BioResources 2008;3:1267-77.

[43] Khiari R, Mhenni MF, Belgacem MN, Mauret E. Valorisation of Vegetal Wastes as a Source of Cellulose and Cellulose Derivatives 2011:80-9. doi:10.1007/s10924-010-0207-y.

[44] Bettaieb F, Khiari R, Dufresne A, Mhenni MFF, Putaux JLL, Boufi S. Nanofibrillar cellulose from Posidonia oceanica: Properties and morphological features. Ind Crops Prod 2015;72:97-106. doi:10.1016/j.indcrop.2014.12.060.

[45] Bettaieb F, Khiari R, Hassan ML, Belgacem MN, Bras J, Dufresne A, et al. Preparation and characterization of new cellulose nanocrystals from marine biomass Posidonia oceanica. Ind Crops Prod 2015;72:175-82. doi:10.1016/j.indcrop.2014.12.038.

[46] Battegazzore D, Bocchini S, Alongi J, Frache A, Marino F. Cellulose extracted from rice husk as filler for poly(lactic acid): preparation and characterization. Cellulose 2014;21:1813-21. doi:10.1007/s10570-014-0207-5.

[47] Urruzola I, Robles E, Serrano L, Labidi J. Nanopaper from almond (Prunus dulcis) shell. Cellulose 2014;21:1619-29. doi:10.1007/s10570-014-0238-y.

[48] Valdés A, Fenollar O, Beltrán A, Balart R, Fortunati E, Kenny JM, et al. Characterization and enzymatic degradation study of poly(??-caprolactone)-based biocomposites from almond agricultural by-products. Polym Degrad Stab 2016;132:181-90. doi:10.1016/j.polymdegradstab.2016.02.023. 
[49] Yang H, Yan R, Chen H, Lee DH, Zheng C. Characteristics of hemicellulose, cellulose and lignin pyrolysis. Fuel 2007;86:1781-8. doi:10.1016/j.fuel.2006.12.013.

[50] Grassie N, Murray EJ, Holmes PA. The thermal degradation of poly(-(d)-??-hydroxybutyric acid): Part 2-Changes in molecular weight. Polym Degrad Stab 1984;6:95-103. doi:10.1016/0141-3910(84)90075-2.

[51] Petinakis E, Liu X, Yu L, Way C, Sangwan P, Dean K, et al. Biodegradation and thermal decomposition of poly(lactic acid)-based materials reinforced by hydrophilic fillers. Polym Degrad Stab 2010;95:1704-7. doi:10.1016/j.polymdegradstab.2010.05.027.

[52] Sanchez-Safont EL, Gonzalez-Ausejo J, Gamez-Perez J, Lagaron JM, Cabedo L. Poly(3Hydroxybutyrate-co-3-Hydroxyvalerate)/ purifi ed cellulose fiber composites by melt blending: characterization and degradation in composting conditions. J Renew Mater 2016;4. doi:10.7569/JRM.2015.634127.

[53] Gatenholm P, Kubát J, Mathiasson A. Biodegradable natural composites. I. Processing and properties. J Appl Polym Sci 1992;45:1667-77. doi:10.1002/app.1992.070450918.

[54] Elena E, Elena M, Râp M, Popa O. PHB / Cellulose fibers based materials : physical , mechanical and barrier properties. Agric Agric Sci Procedia 2015;6:608-15. doi:10.1016/j.aaspro.2015.08.099.

[55] Puglia D, Fortunati E, D'Amico D a., Manfredi LB, Cyras VP, Kenny JM. Influence of organically modified clays on the properties and disintegrability in compost of solution cast poly(3-hydroxybutyrate) films. Polym Degrad Stab 2014;99:127-35. doi:10.1016/j.polymdegradstab.2013.11.013.

[56] Weng Y-X, Wang Y, Wang X-L, Wang Y-Z. Biodegradation behavior of PHBV films in a pilot- 
scale composting condition. Polym Test 2010;29:579-87.

doi:10.1016/j.polymertesting.2010.04.002.

[57] Arrieta MP, López J, Rayón E, Jiménez a. Disintegrability under composting conditions of plasticized PLA-PHB blends. Polym Degrad Stab 2014:1-12.

doi:10.1016/j.polymdegradstab.2014.01.034. 


\section{Figure Captions:}

Figure 1. Schematic representation of the treatments applied to the three residues (AS, RH and SG) and the visual appearance before and after the treatment

Figure 2. Purification fiber results: a)FTIR spectra of AS, RH and SG fibers before and after the treatment; b) WAXS patterns of AS, RH and SG fibers before and after the treatment; c) Crystallinity index of AS, RH and SG fibers before and after the treatment; d) DTG curves of AS, RH and SG fibers before and after the treatment

Figure 3. SEM micrographs of AS (a-c), RH (d-f) and SG (g-i) fibers before treatment (left), after treatment (center) and high magnification image after treatment (right)

Figure 4. SEM micrographs of PHB/AS (a-c), PHB/RH (d-f) and PHB/SG (g-i) composites with 10 phr fiber content (left), $20 \mathrm{phr}$ fiber content (center) and detail of fiber-matrix interface (right)

Figure 5. Young's modulus and tensile strength (a) and elongation at break (b) of neat PHB and $\mathrm{PHB} /$ fiber composites

Figure 6. Water Vapor Permeability (WVP) of neat PHB and PHB/fiber composites

Figure 7. a) Photographs of neat $\mathrm{PHB}$ and $\mathrm{PHB} / 10$ AS thermoforming trays as a function of heating time, b) representative thermoforming trays of $\mathrm{PHB} /$ fiber composites, $\mathrm{c}$ ) Sheet temperature as a function of heating time, $d$ ) thermoforming temperature range for neat $\mathrm{PHB}$ and PHB/10 AS composite

Figure 8. Disintegration of neat PHB and PHB/fiber composites over time under composting conditions

Figure 9. Visual appearance of neat PHB and PHB/fiber composites at 0 days (left) and 28 days (right) of composting

\section{Table Headings:}

Table 1. Composition and treatment yield of AS, RH and SG

Table 2. TGA and DSC data of PHB and PHB/fiber composites 


\section{Almond Shell}

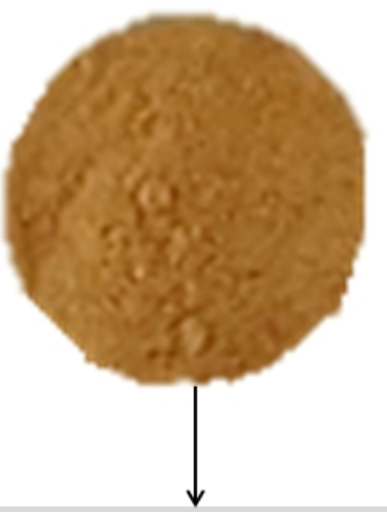

Sieving $(140 \mu \mathrm{m})$

Drying $\left(60^{\circ} \mathrm{C}, 24 \mathrm{~h}\right)$
Rice Husk

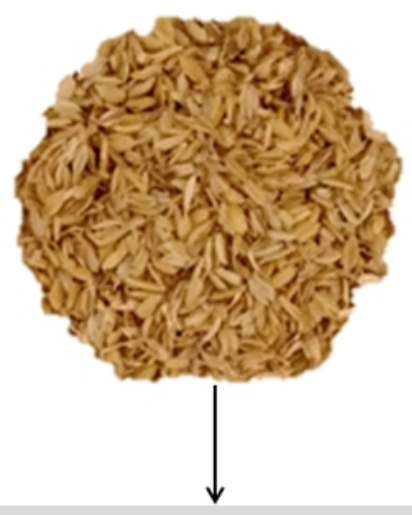

Ultracentrifugal milling

$(125 \mu \mathrm{m})$

Drying $\left(60^{\circ} \mathrm{C}, 24 \mathrm{~h}\right)$

\section{Seagrass}

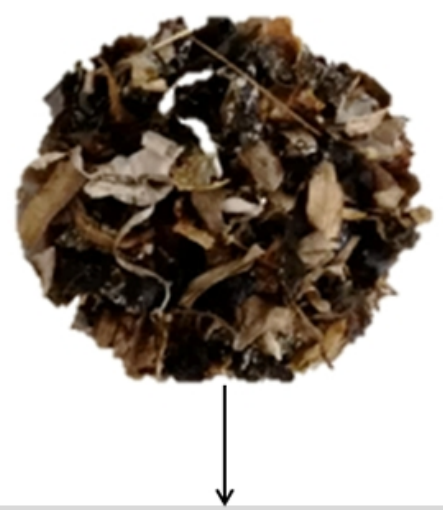

Ultracentrifugal milling $(125 \mu \mathrm{m})$ Drying $\left(60^{\circ} \mathrm{C}, 24 \mathrm{~h}\right)$ Pretreatment (3\% v/v $\mathrm{CH}_{3} \mathrm{COOH}$ )

\section{Treatment: \\ $5 \%$ wt/v $\mathrm{NaOH}, 80^{\circ} \mathrm{C}(\mathrm{x} 2)$ \\ $10 \% \mathrm{v} / \mathrm{v} \mathrm{H}_{2} \mathrm{O}_{2}, 80^{\circ} \mathrm{C}(\mathrm{x} 2)$}

Grinding and sieving $(140 \mu \mathrm{m})$ Drying $\left(60^{\circ} \mathrm{C}, 24 \mathrm{~h}\right)$
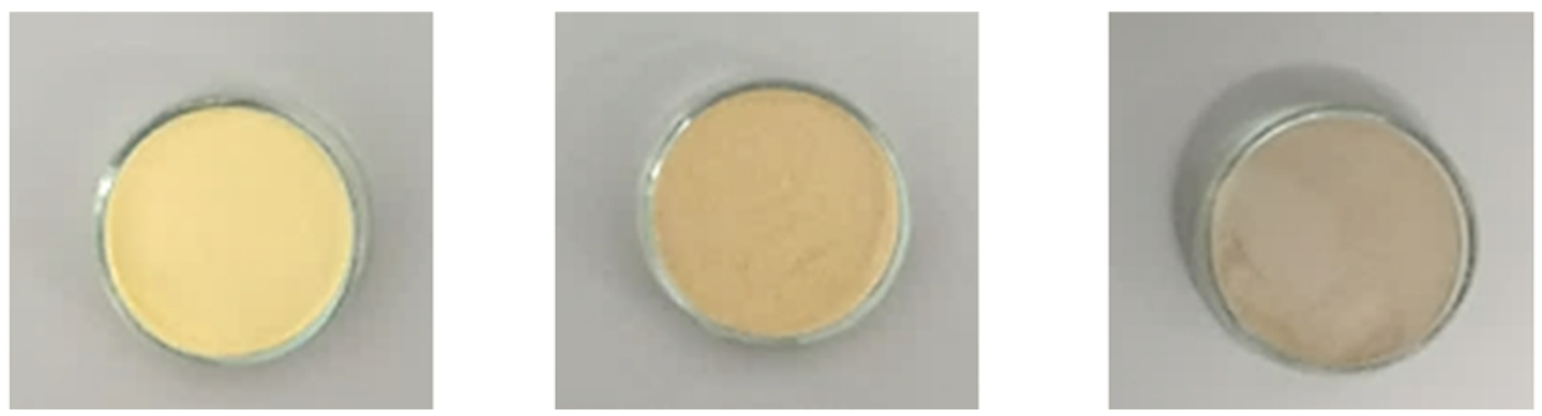


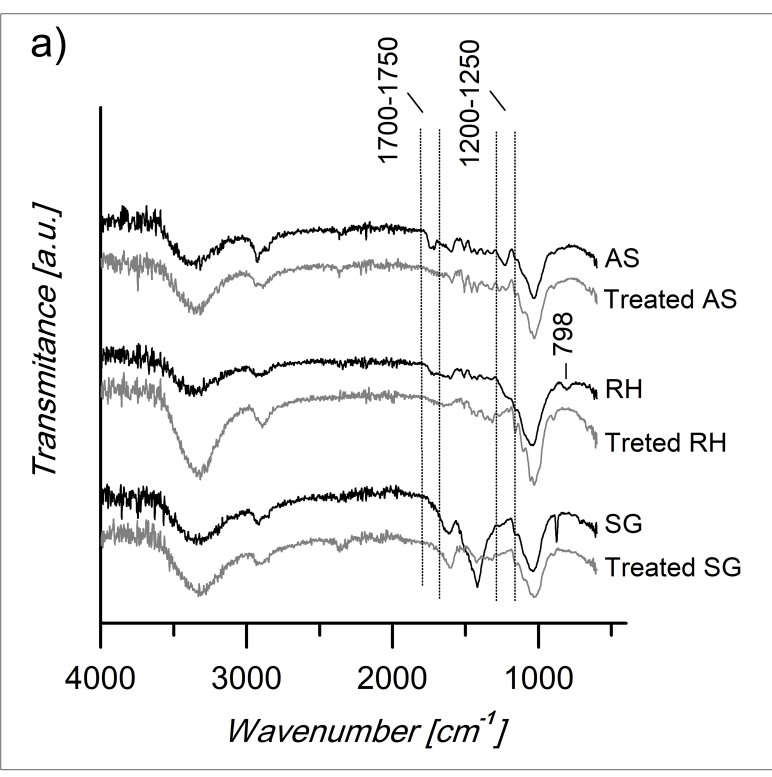

b).

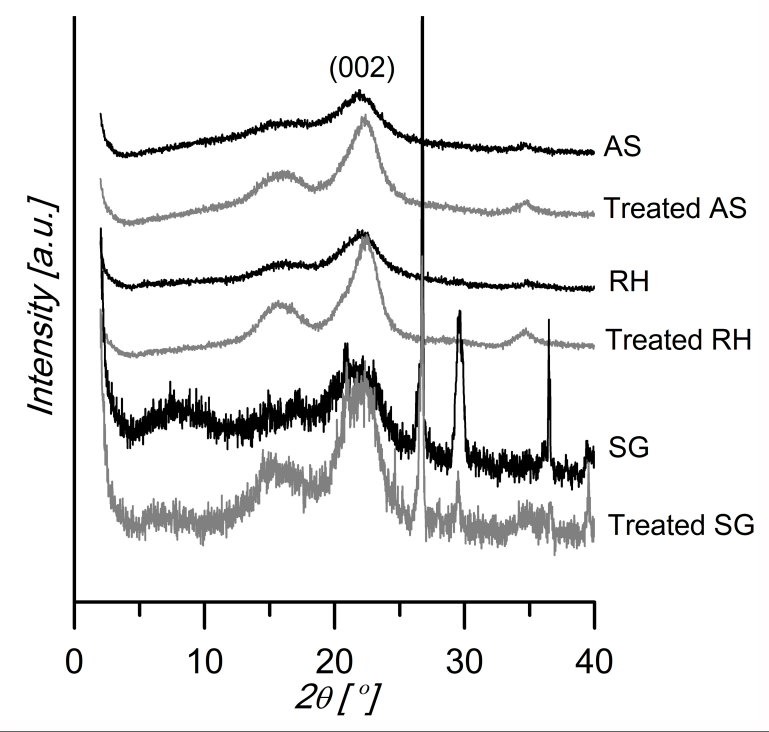

d)

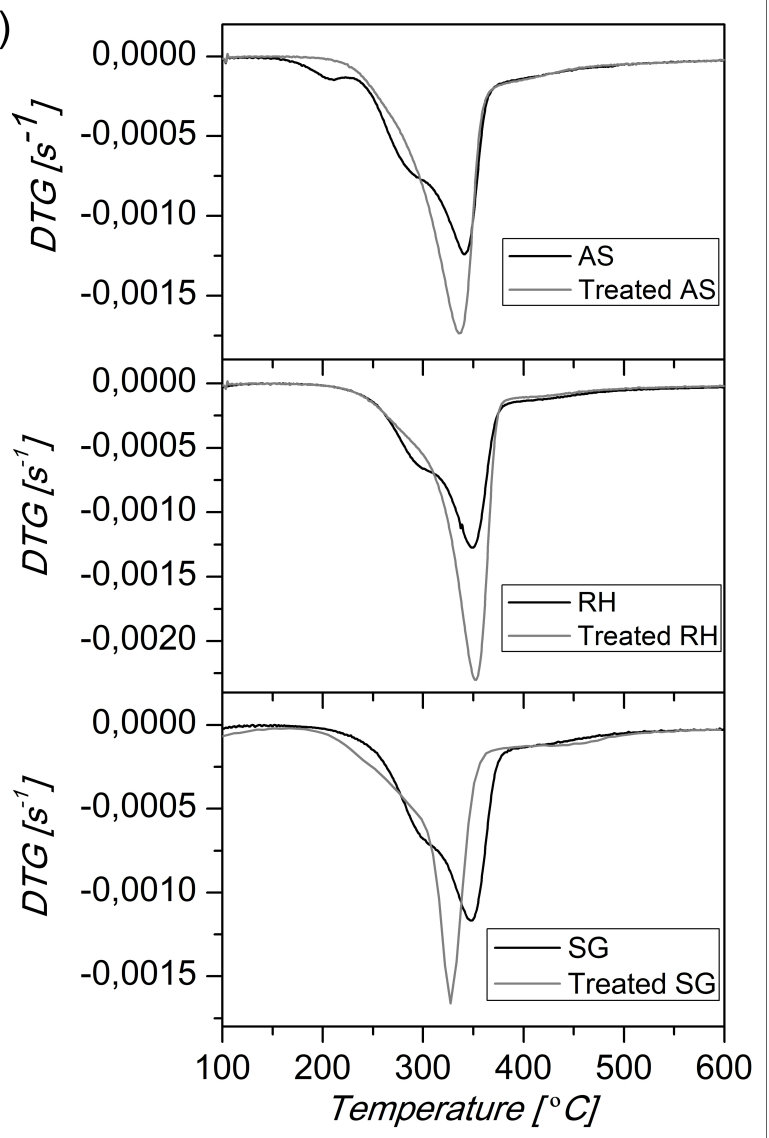

c)

\begin{tabular}{|c|c|c|}
\cline { 2 - 3 } \multicolumn{1}{c|}{} & \multicolumn{2}{c|}{$\mathrm{Ci}(\%)$} \\
\cline { 2 - 3 } \multicolumn{1}{c|}{} & Untreated & Treated \\
\hline AS & 42 & 57 \\
\hline RH & 47 & 66 \\
\hline SG & 30 & 50 \\
\hline
\end{tabular}




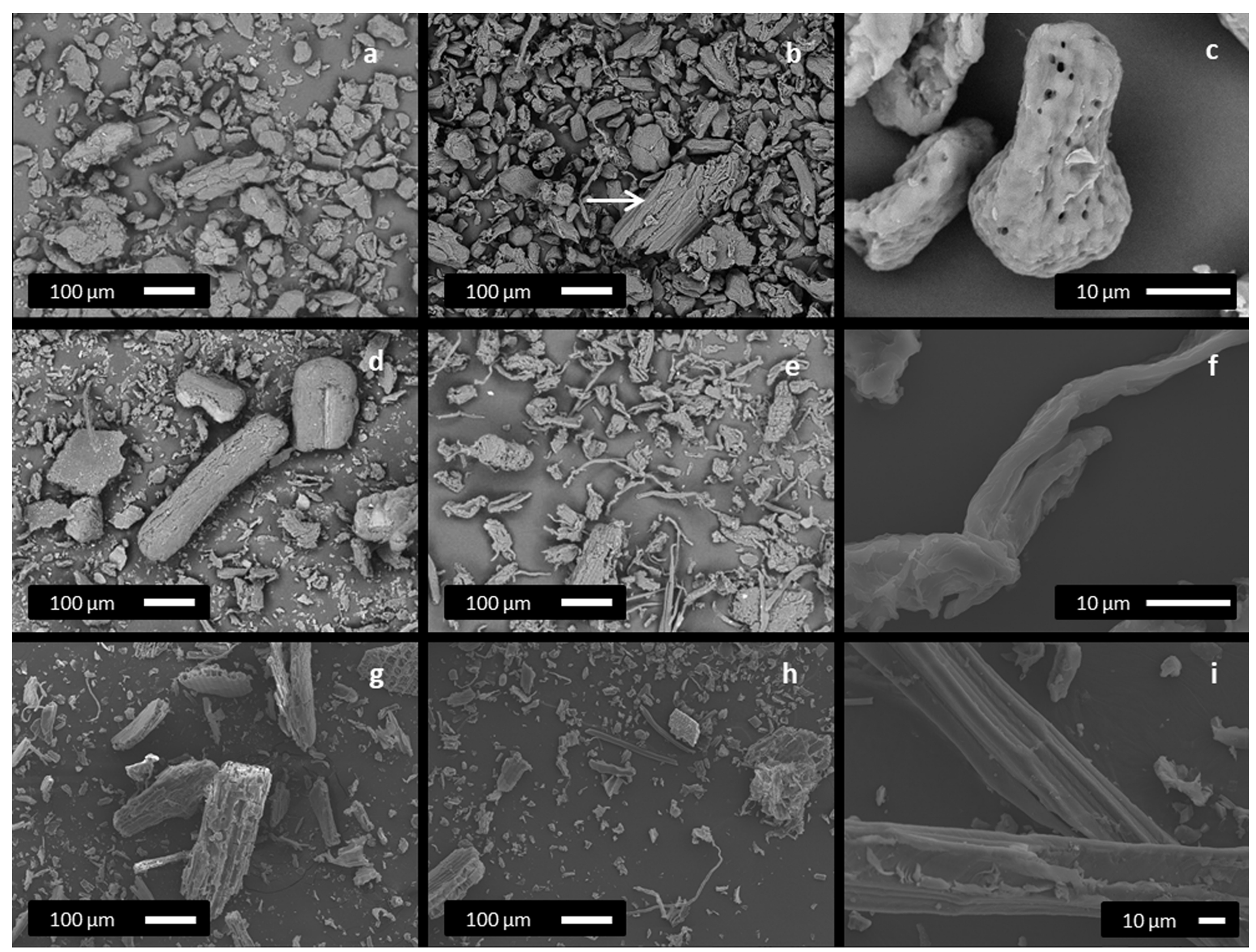




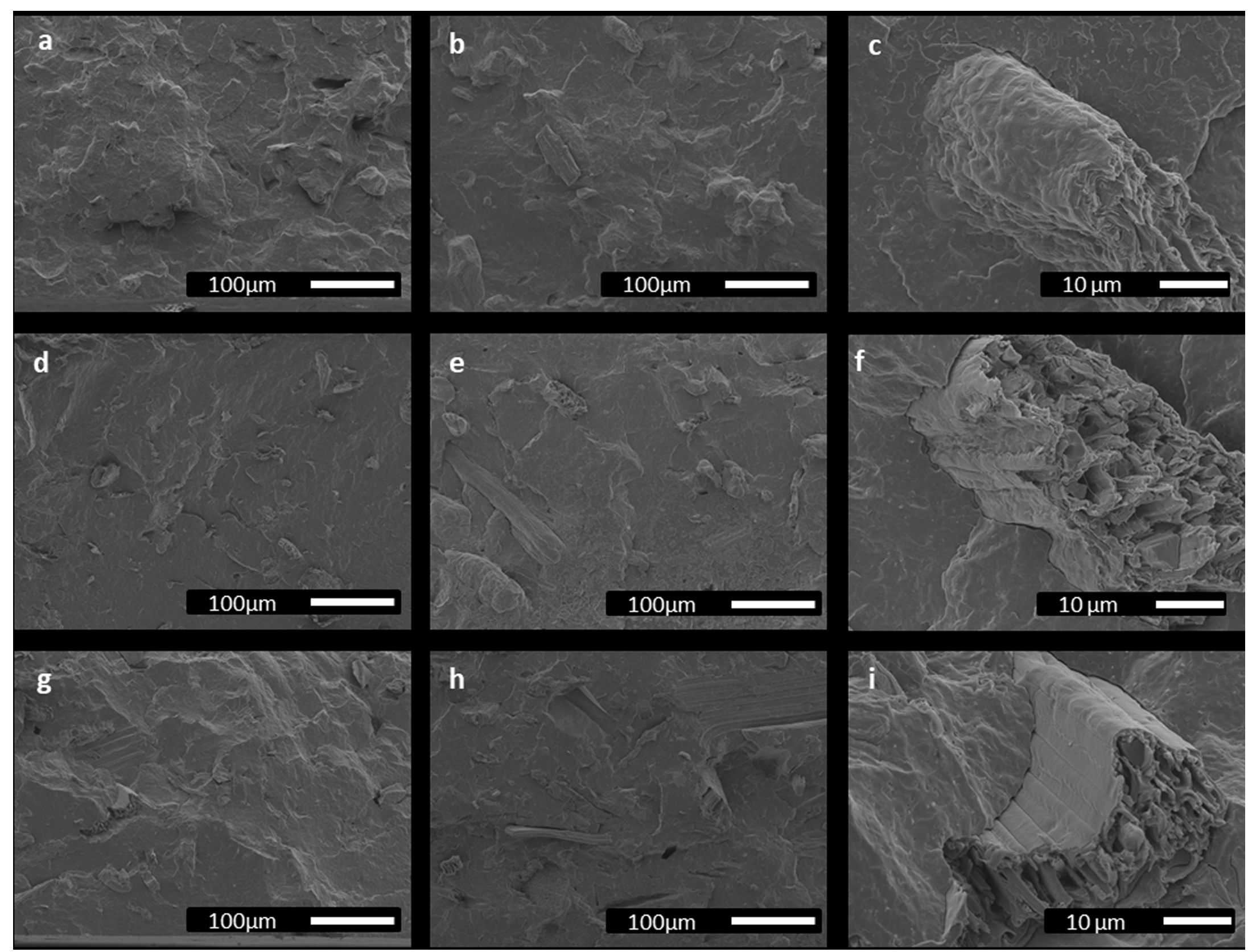



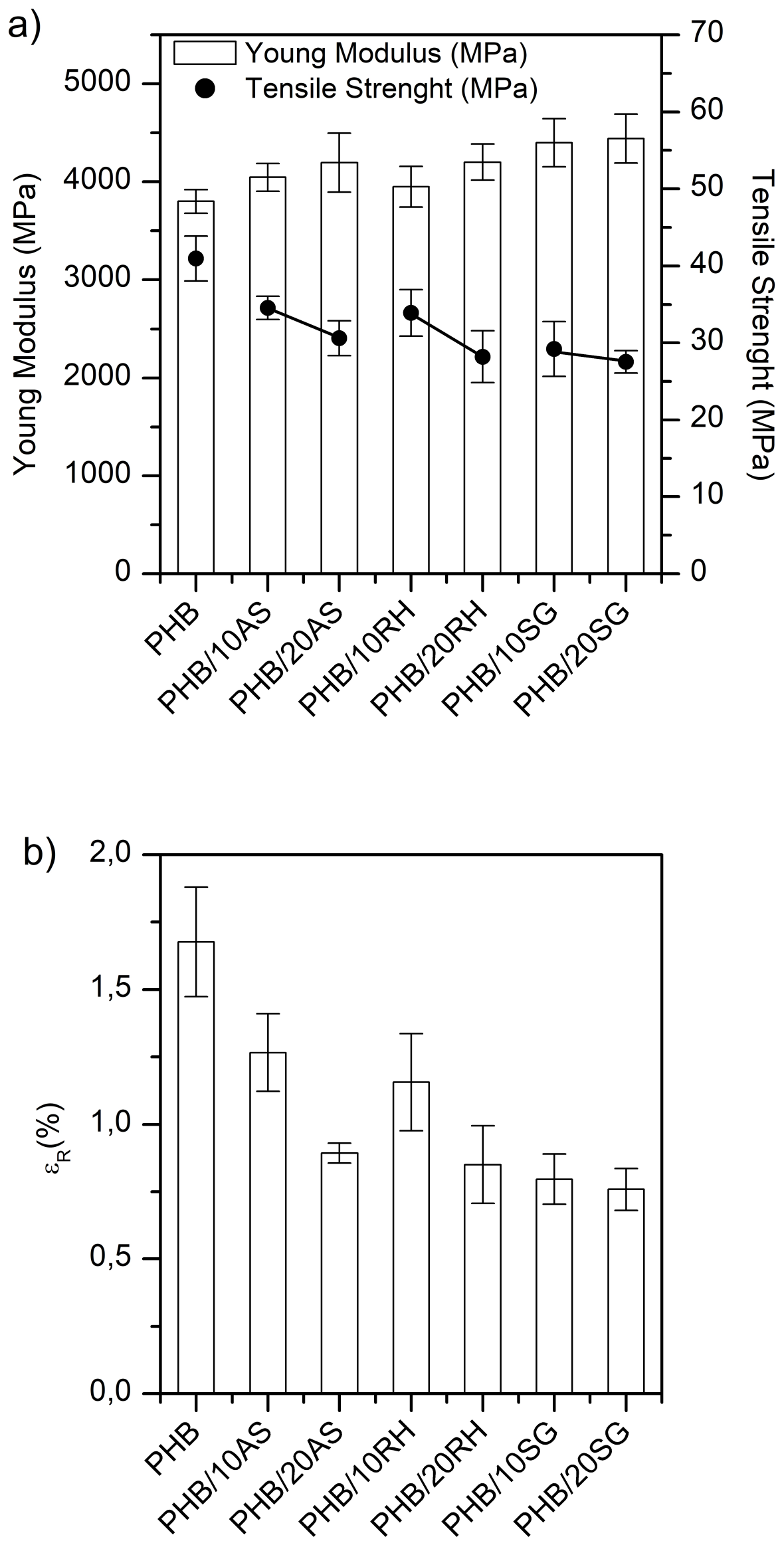


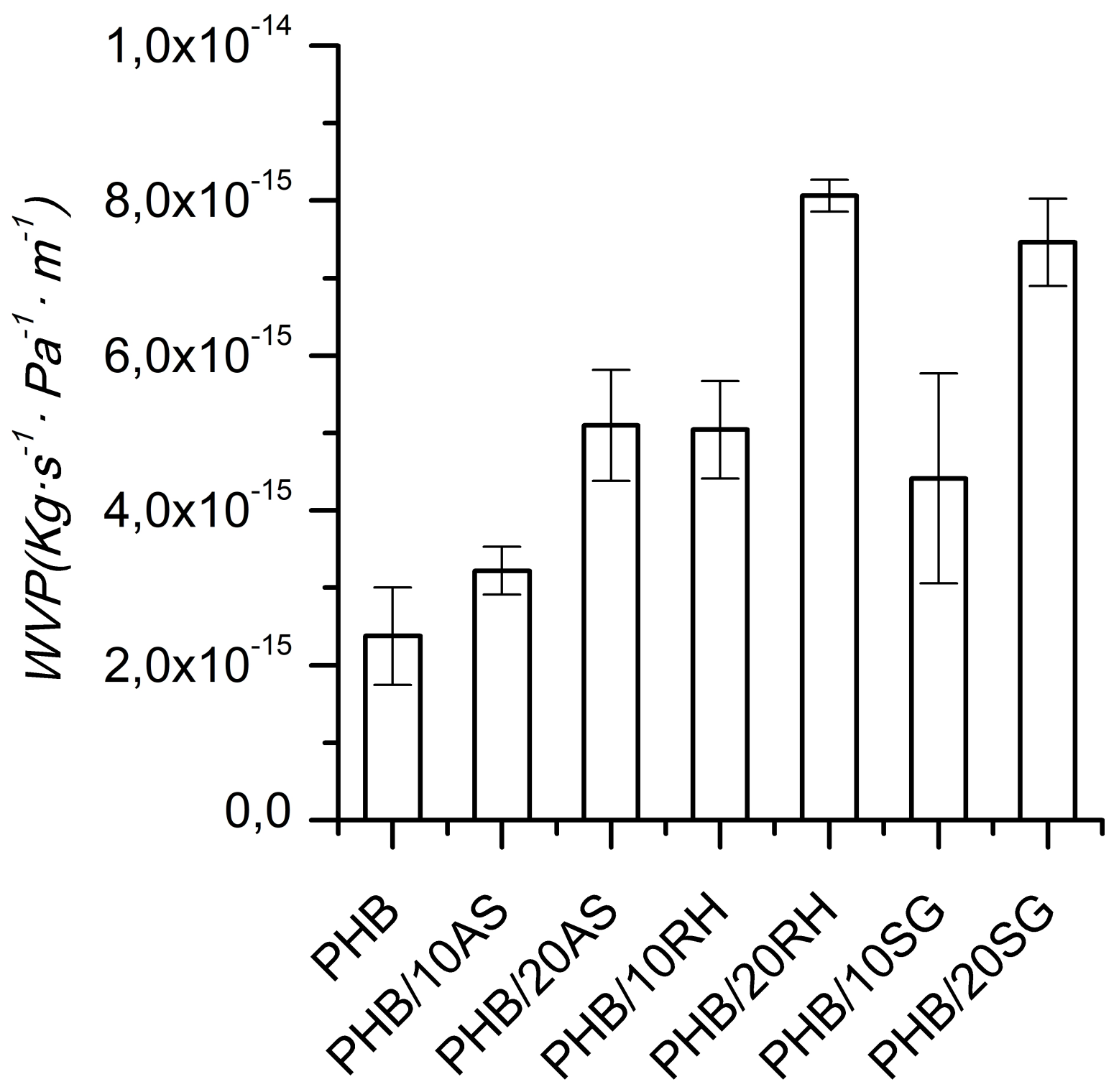




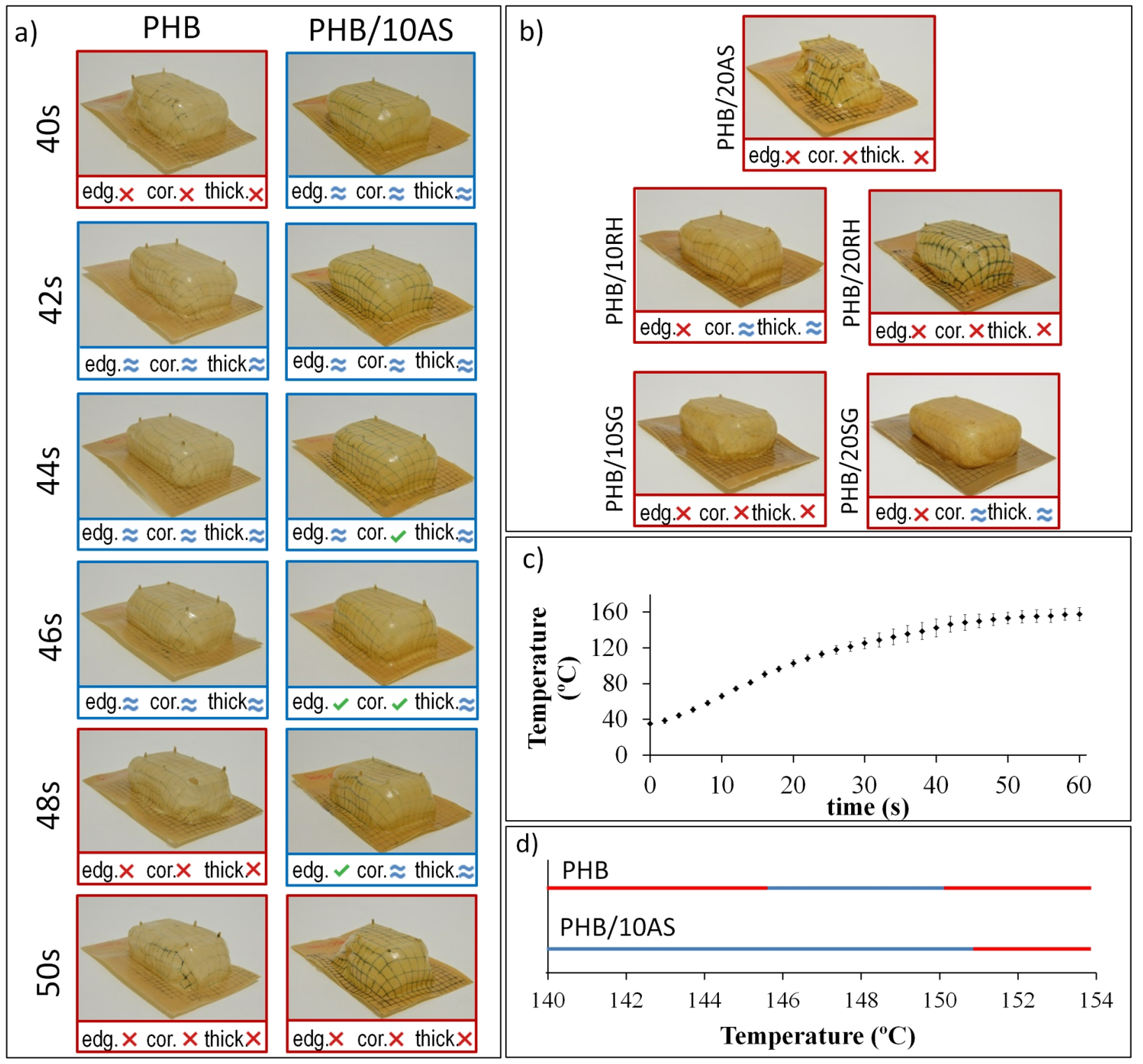




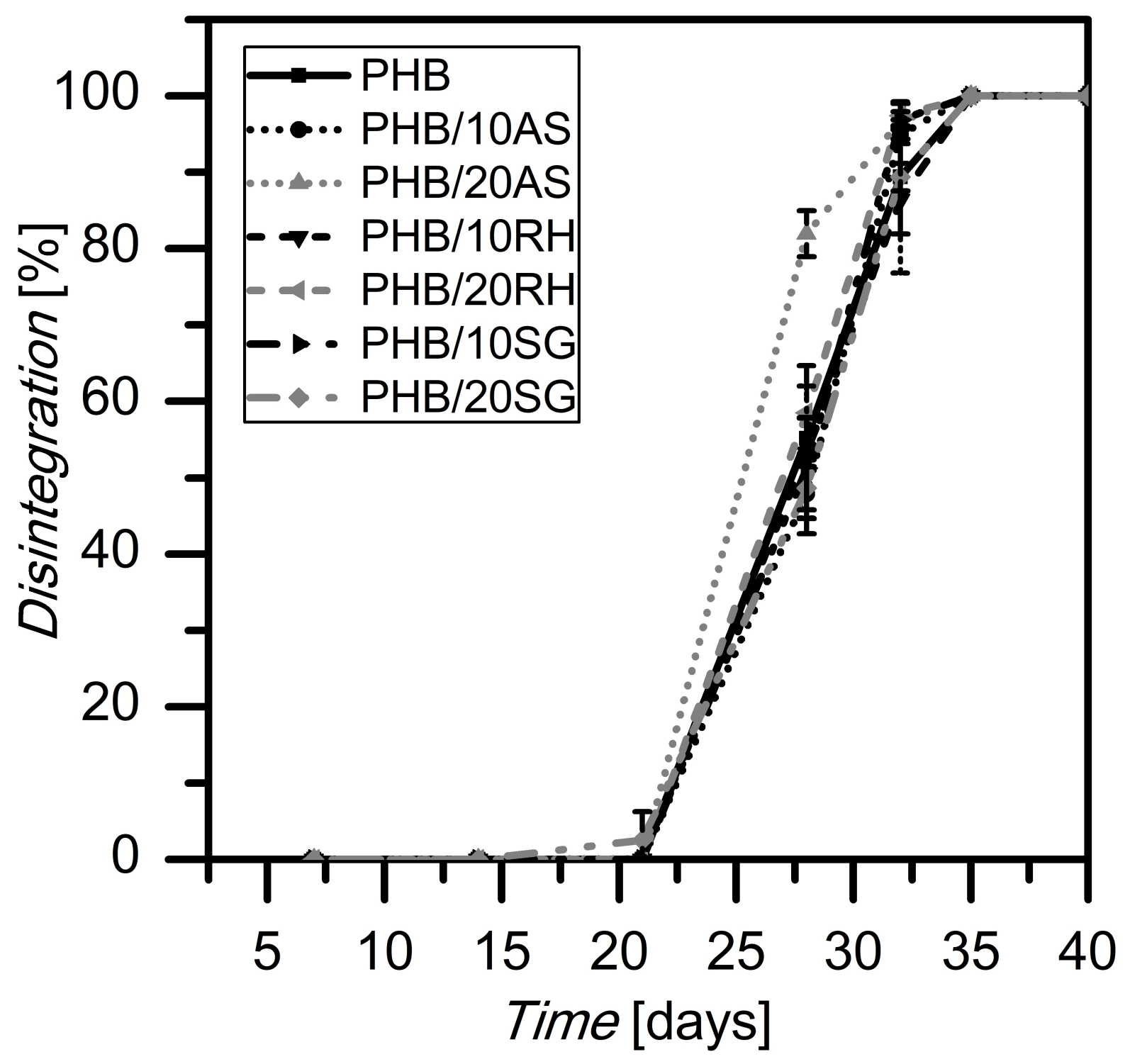




\section{PHB}

PHB/10AS
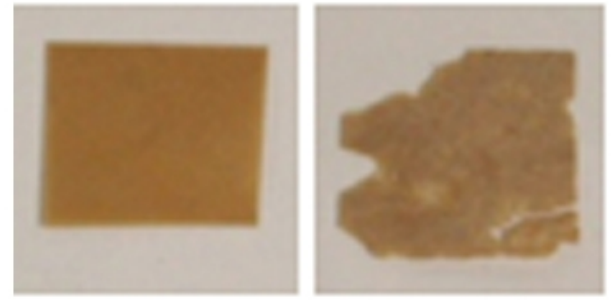

$\mathrm{PHB} / 10 \mathrm{RH}$

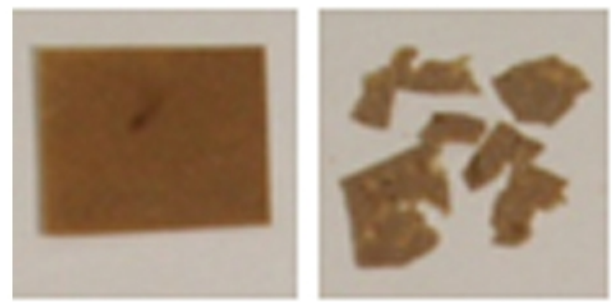

PHB/10SG
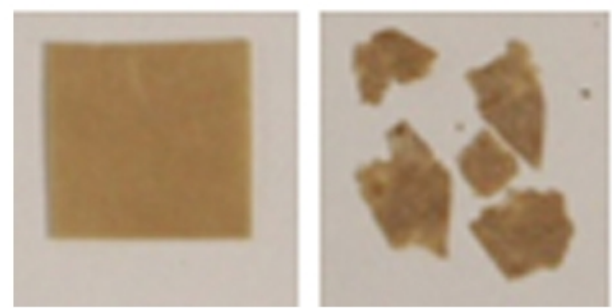

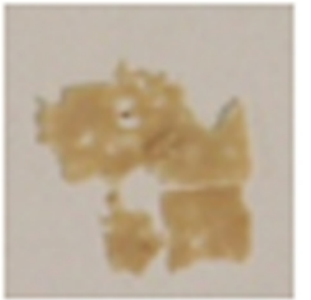

PHB/20AS
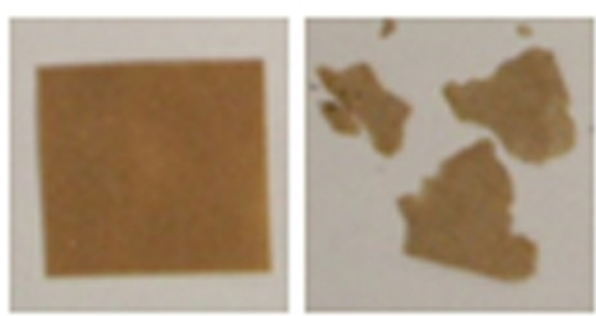

$\mathrm{PHB} / 20 \mathrm{RH}$

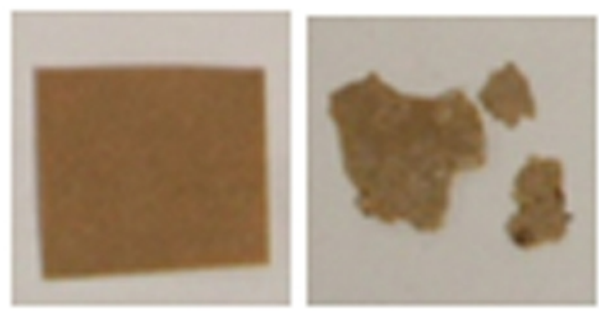

$\mathrm{PHB} / 20$ SG

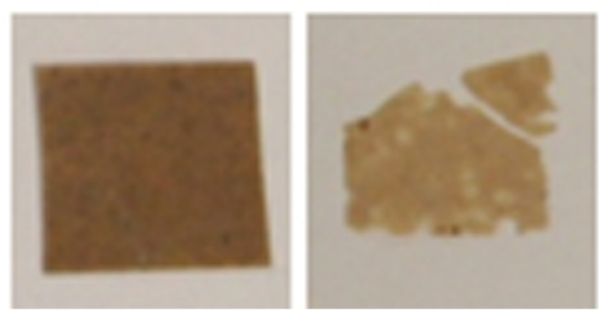


AS

RH

SG

\begin{tabular}{|l|l|l|l}
\hline Moisture (\%)* & $8.6 \pm 2$ & $6.5 \pm 0.1$ & $5.6 \pm 0.1$ \\
\hline Ash (\%)* & $18 \pm 0.4$ & $20.2 \pm 0.2$ & $19 \pm 3$ \\
\hline Holocellulose (\%)** & $53.81^{\text {a) }}$ & 49,72 & $59^{\mathrm{d})}$ \\
\hline Hemicelluloses (\%)** & $7.56^{\text {a) }}$ & $18.6^{\mathrm{b})}$ & $21^{\mathrm{d})}$ \\
\hline Cellulose(\%)** & $46.25^{\mathrm{a})}$ & $31.13^{\mathrm{b})}$ & $38^{\mathrm{d})}$ \\
\hline Lignin(\%)** & $29.85^{\mathrm{a})}$ & $28.25^{\mathrm{b}}$ & $27^{\mathrm{d})}$ \\
\hline Silica (\%)** & - & $15-17^{\mathrm{c})}$ & - \\
\hline Treatment Yield(\%)* & $45 \pm 4$ & $41 \pm 5$ & $33 \pm 1$ \\
\hline
\end{tabular}

${ }^{*}$ This study

**Bibliography reported values: a)(Danish et al., 2015) , b)(Wang et al., 2016),c)(Arjmandi et al., 2015), d)(Ncibi et al., 2009) 



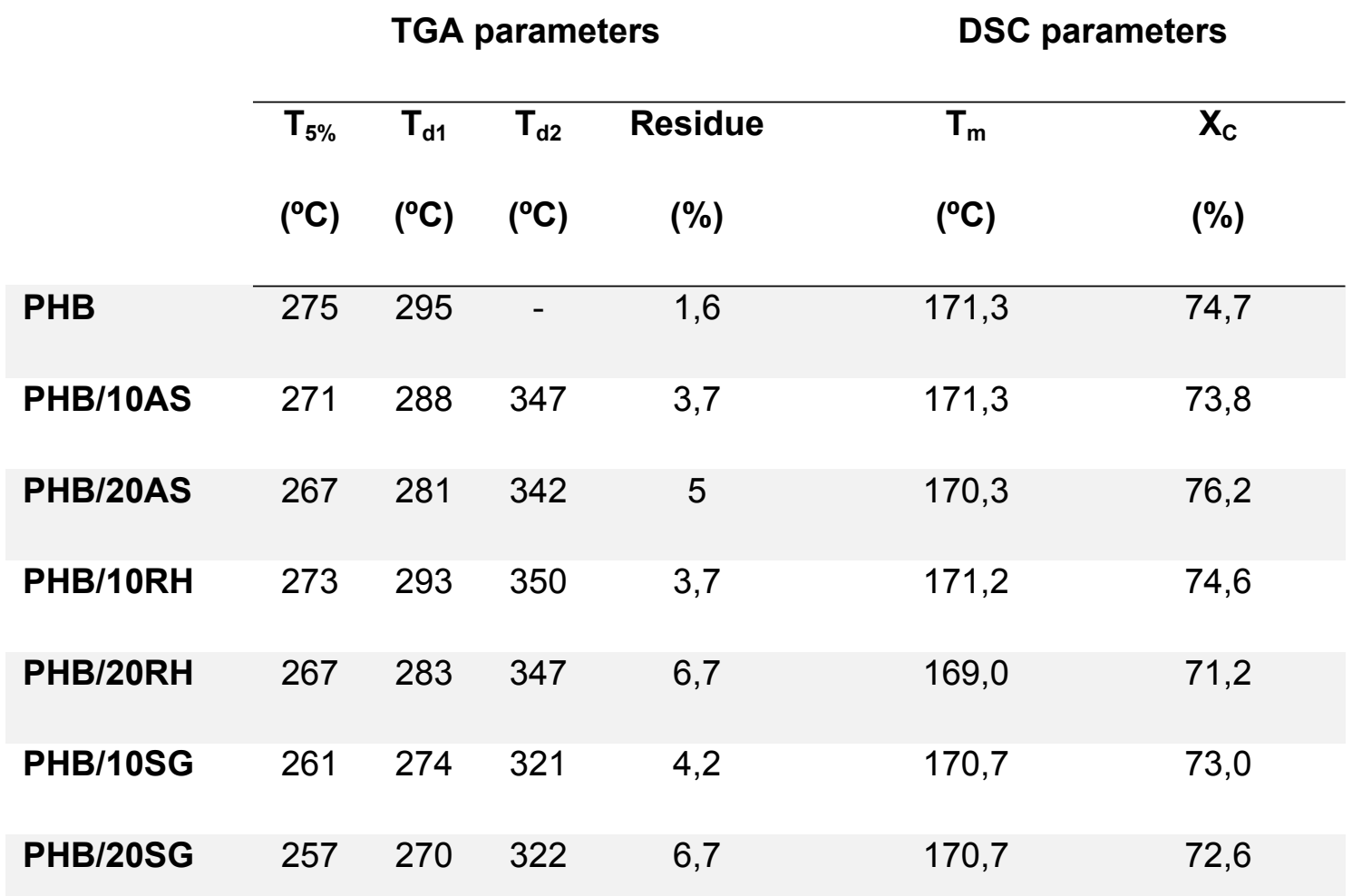

